\title{
Management of advanced kidney cancer: Canadian Kidney Cancer Forum 2013 Consensus Update
}

\section{Canadian Kidney Cancer Forum 2013}

Scott North, MD, FRCPC; Naveen Basappa, MD; Georg Bjarnason, MD, FRCPS(C); Normand Blais, MD, FRCSC; Christina Canil, MD, FRCPC; Daniel Heng, MD, MPH; Jennifer Knox, MD, MSC, FRCPC; Neil Reaume, MD FRCPC; Dean Ruether, MD, FRCPC; Denis Soulières, MD, MSc., FRCPC; Pawel Zalewski, MD, FRCPC; Peter Black, MD, FRCSC; Rodney Breau, MD, FRCSC; Michael Jewett, MD, FRCSC; Anil Kapoor, MD, FRCSC; Jean-Baptiste Lattouf, MD, FRCSC; Ronald Moore, MD, PhD, FRCSC; Ricardo Rendon, MD, FRCSC; Gerald Todd, MD, FRCSC; Edith Pituskin, PhD; Craig Gedye, MBChB, FRACP, PhD; Lori Wood, MD, MSC(Epi), FRCPC on behalf of the Kidney Cancer Research Network of Canada

Cite as: Can Urol Assoc J 2013;7(7-8):238-43. http://dx.doi.org/10.5489/cuaj.536 Published online August 19, 2013.

$\mathrm{T}$ his is the fourth report from the Kidney Cancer Research Network of Canada (KCRNC) with an update from the fourth Canadian Kidney Cancer Forum held in January 2013 in Toronto, Ontario, Canada. ${ }^{1-3}$

Kidney cancer, predominantly renal cell carcinoma (RCC), is the most lethal genitourinary malignancy and kills more than 1700 Canadians a year. ${ }^{4}$ The overall incidence is increasing by $2 \%$ per year for unknown reasons; most new cases are small renal masses. Targeted systemic therapies, which have been integrated into clinical practice with evolving experience, have been available for more than 7 years. Preservation of kidney function with widespread adoption of partial nephrectomy is a focus of treatment of early stage disease. These and other advances have revolutionized care and stimulated research. There are several guidelines in Canada that address various aspects of RCC patient care., ${ }^{2,3,5,6}$

Three previous forums were held in 2008, 2009 and 2011. As before, this 2013 meeting was small, by invitation and attended by survivors, caregivers, expert clinicians and researchers in kidney cancer field. The attendees included representatives of Kidney Cancer Canada. ${ }^{7}$

During the conference, prior consensus statements were reviewed and updated using the same process. This report is an update of the advanced disease management component of the consensus published in $2011 .^{3}$ The Forum again addressed the following: (1) strategies for kidney cancer control in Canada, which includes the now operational Canadian Kidney Cancer Information System (CKCis); (2) the development of a coordinated approach to validating the proposed genetic testing guidelines for patients and families at risk for kidney cancer; (3) the fostering of an increased awareness of cancer survivorship issues, espe- cially the development of a survivorship care plan; and (4) the continuation of the quality process to validate the now defined quality indicators for the management of kidney cancer. Meeting participants also discussed the delivery models of genetic testing and counselling for patients with kidney cancer and the need for the availability of services for patients with potentially hereditary cancers. Finally, a number of new research initiatives for the "personalized medicine" care of kidney cancer were proposed. These will be the subject of future reports. This consensus statement pertains to the management of advanced disease. A separate document discussing early disease, including diagnosis and surgical management, will be published as a separate document.

\section{Management of locally advanced kidney cancer}

\section{Neoadjuvant therapy}

There is no indication for neoadjuvant therapy prior to planned surgical resection outside the context of a clinical trial.

If patients are felt to be surgically resectable at diagnosis, they should proceed immediately to surgery. Routine use of neoadjuvant therapies is not indicated at this time. The final results of clinical trials with adjuvant and neoadjuvant anti-angiogenic agents (vascular endothelial growth factor receptor tyrosine kinase inhibitors [VEGFr TKI], VEGF antibodies or mammalian target of rapamycin [mTOR] inhibitors) will not be available for several more years. Some patients deemed inoperable at diagnosis may have a dramatic response to targeted therapy and if there is any question that they may have converted to an operable state, they should be re-evaluated by a urologist. 


\section{Adjuvant therapy}

There is no indication for adjuvant therapy after surgical resection, unless in the context of a clinical trial.

Adjuvant therapy with cytokines does not improve overall survival after nephrectomy. ${ }^{8}$ The results of several clinical trials with adjuvant anti-angiogenic agents (VEGFr TKI, VEGF antibodies or mTOR inhibitors) will not be available for several more years. Patients with high-risk tumours, who have undergone complete resection, should be encouraged to participate in clinical trials whenever possible.

\section{Advanced (metastatic) kidney cancer}

Enrolling patients in well-designed clinical trials should always be the first option for patients with advanced or metastatic RCC.

\section{First-line therapy}

- Targeted therapy is the preferred treatment (Table 1).

- Observation can also be considered, for some patients with slow growing asymptomatic disease.

- High-dose interleukin-2 (IL-2) can be considered in highly selected patients.

The field of systemic therapy is evolving quickly and the recommendations made in this document reflect the available evidence at the time the consensus conference participants reached their conclusions. As new data become available, the treatment options will invariably change.

RCC is a heterogeneous disease and there are several prognostic factors that may help clinicians risk stratify their patients. These include clinical factors, such as patient performance status, and laboratory parameters. The first of these prognostic scores was published by Motzer and colleagues and was used to define entry criteria or to stratify for patient enrolment in clinical trials. ${ }^{9}$ It is for this reason that the treatment recommendations in Table 1 and the text below differ based on patient risk. This prognostication system was developed in the cytokine era. In the targeted therapy era, Heng and colleagues have published a similar, but not identical, risk stratification score which is applicable to patients receiving therapy today. ${ }^{10}$

Based on phase III clinical trial data, sunitinib produces higher response rates, improved quality of life (QOL) and a longer progression-free survival (PFS) than interferonalfa in patients with metastatic clear cell RCC (mRCC). ${ }^{11}$ Subsequent survival analysis showed that patients treated with sunitinib had a longer overall survival (OS) than those treated with interferon. ${ }^{12}$ In addition, population-based studies from British Columbia and Alberta have shown an almost doubling of OS of mRCC since the introduction of sunitinib and sorafenib. ${ }^{13,14}$ The dose and schedule of sunitinib should be optimized for each patient to derive the most benefit. This may require adjustments from the standard 4-week on/2-week off dosing schedule. ${ }^{15}$ Based on phase III data, pazopanib produces an improvement in PFS compared to placebo in both cytokine naïve and refractory patients. ${ }^{16}$ As first-line therapy, pazopanib has also been shown to be non-inferior to sunitinib with respect to PFS in the phase III COMPARZ (COMParing the efficacy, sAfety and toleRability of paZopanib vs. sunitinib) clinical trial (abstract information only). ${ }^{17}$ Another VEGFr TKI, tivozanib, has demonstrated superior PFS compared to sorafenib in a phase III clinical trial of patients with clear cell RCC who were either treatment naïve or had no more than 1 prior line of therapy (excluding VEGFr TKI or mTOR inhibitors). ${ }^{18}$

Based on phase III data, temsirolimus produces an improvement in PFS and OS in poorer risk patients than interferon alone or combined temsirolimus and inter-

\begin{tabular}{|c|c|c|c|}
\hline Setting & Patients & $\begin{array}{c}\text { Therapy } \\
\text { (Level } 1 \text { evidence) }\end{array}$ & $\begin{array}{c}\text { Other options } \\
\text { (Less than Level } 1 \text { evidence) }\end{array}$ \\
\hline \multirow[t]{2}{*}{ Untreated } & Good or intermediate risk & $\begin{array}{c}\text { Sunitinib } \\
\text { Bevacizumab+IFN* } \\
\text { Pazopanib } \\
\text { Tivozanib** }\end{array}$ & $\begin{array}{c}\text { HD IL-2 } \\
\text { Sorafenib } \\
\text { Observation }\end{array}$ \\
\hline & Poor risk & Temsirolimus & Sunitinib \\
\hline \multirow{3}{*}{ Second-line } & Cytokine refractory & $\begin{array}{l}\text { Sorafenib } \\
\text { Pazopanib } \\
\text { Tivozanib** } \\
\text { Axitinib }\end{array}$ & Sunitinib, bevacizumab+IFN* \\
\hline & Prior VEGF targeted therapy & $\begin{array}{l}\text { Everolimus } \\
\text { Axitinib }\end{array}$ & Targeted therapy not previously used \\
\hline & Prior mTOR & & VEGFr TKI \\
\hline Third line $e^{* * *}$ & Any & & Targeted therapy not previously used \\
\hline \multicolumn{4}{|c|}{$\begin{array}{l}\text { IFN: interferon; HD IL-2: high-dose interleukin-2; VEGF: vascular endothelial growth factor; VEGFr TKI: VEGF receptor-tyrosine kinase inhibitor; mTOR: mammalian target of rapamycin. } \\
{ }^{*} \text { The combination of bevacizumab + IFN has not been approved in Canada but is approved in the United States and Europe. **At the present time, tivozanib has not received Health Canade } \\
\text { approval. ***At the present time, there is no Health Canada approved third line systemic therapy. }\end{array}$} \\
\hline
\end{tabular}


feron. ${ }^{19}$ Poorer risk was defined by at least $3 / 6$ of the following criteria: Karnofsky Performance Scale (KPS) 60-70; $\uparrow \mathrm{Ca}++$; $\downarrow$ hemoglobin; $\uparrow$ lactate dehydrogenase; $<1$ year from nephrectomy to treatment; or multiple metastatic sites. Where drug access is limited, everolimus, if available, would be a reasonable alternative. ${ }^{20}$ In patients with intolerance to sunitinib, pazopanib, temsirolimus or sorafenib remain good options. ${ }^{21}$

There is phase III data demonstrating that combined bevacizumab and interferon improves PFS over interferon alone. ${ }^{22,23}$ At this time, there has not been an application submitted regarding bevacizumab for use in kidney cancer in Canada; therefore, it is not an option for Canadian patients.

The meeting attendees determined that an initial period of observation is reasonable in select patients, given that no systemic therapies are currently considered curative, that all available treatments can have side effects, and that some patients may experience an indolent clinical course with slowly growing asymptomatic metastases.

No phase III studies on the use of IL-2 have shown an improvement in survival, and thus it is not considered a standard of care, but may be in highly selected patients. Based on phase II data, however, a very select group of patients may be considered for high-dose IL-2. ${ }^{24}$ High-dose IL-2 must be delivered in specialized and experienced centres and ideally in the context of a clinical trial or investigational setting. Low-dose IL-2 should not be given. ${ }^{25,26}$

In patients with metastatic or advanced RCC with nonclear cell histology, enrolment in clinical trials should be encouraged. Other options include: sunitinib, based on subgroup analyses from the Expanded Access trial showing safety and activity; sorafenib, based on subgroup analyses from the Advanced Renal Cell Carcinoma Sorafenib (ARCCS) expanded access trial showing safety and activity; and temsirolimus, based on subgroup analysis of phase III data. ${ }^{27-30}$ In patients with advanced or metastatic sarcomatoid or poorly differentiated RCC, options include: sunitinib, based on prospective, non-randomized data from the Expanded Access Program; sorafenib, based on prospective, non-randomized data from the ARCC expanded access trial; chemotherapy, based on phase II data utilizing agents, such as 5-fluorouracil, gemcitabine, doxorubicin, and combinations of these showing activity; and temsirolimus, based on subgroup analysis from the pivotal phase III trial in which these patients were eligible..$^{27-29,31}$

When prescribing systemic therapy for advanced or metastatic RCC, several key factors must be taken into account. An oncology specialist should prescribe therapy; this person should know about acute and long-term toxicities, drug interactions, and monitoring treatment and response. Patients should be managed in a multidisciplinary environment with adequate resources, including nursing care, dietary care and pharmacy support. Patients must be evaluated frequently to ensure toxicities are recognized and managed appropriately. Patients and caregivers should be provided with information concerning potential side effects and their prevention, treatment and management.

\section{Progression on or intolerance to cytokines}

Based on phase III data, sorafenib improved PFS compared to best supportive care alone in previously treated patients who had received IL-2 or interferon. ${ }^{32}$ OS data were confounded by crossover, but reached significance when censored for crossover. Pazopanib has also been studied in this patient population and improves PFS compared to placebo. ${ }^{16}$ Axitinib has also shown an improvement in PFS compared to sorafenib in this population. In the AXIS (axitinib vs. sorafenib in advanced RCC) trial, about one-third of the subjects had received first-line cytokines at the time of study enrolment and PFS was prolonged with the use of axitinib. ${ }^{33}$ Similarly, tivozanib has shown superior PFS compared to sorafenib in this population. ${ }^{18}$ Sunitinib is an alternate treatment. Based on two phase II trials, sunitinib produced significant response rates and increased PFS compared to historical controls. ${ }^{34}$

\section{Progression after first-line targeted therapy}

\section{- Clinical trials in this population should be supported as the optimal sequence of therapies is unknown. \\ Switch to another targeted agent (Table 1).}

Based on phase III data, everolimus (oral mTOR inhibitor) produced a significantly longer PFS than placebo, with an acceptable toxicity profile in patients who had failed sunitinib or sorafenib (or both). ${ }^{35}$ Should everolimus not be available, temsirolimus should not routinely be substituted given its inferior outcomes when compared to sorafenib in this patient population as shown in the INTORSECT study. ${ }^{36}$

Based on the phase III AXIS trial, axitinib has shown improved PFS compared to sorafenib as second-line therapy in patients progressing after first-line therapy with sunitinib and would be another reasonable second-line option. ${ }^{33}$

At this time, there is no evidence to help determine which second-line therapy after VEGFr TKI is superior, thus everolimus or axitinib would be suitable choices.

In patients with advanced or metastatic RCC post-sunitinib or sorafenib failure, other options include: switching to another VEGFrTKI (e.g., from sunitinib to sorafenib or from sorafenib to sunitinib) based on emerging data showing activity with sequential therapy. ${ }^{37}$ The role of interferon post-targeted therapy is unclear.

For patients whose first-line therapy was an mTOR inhibitor, there is no Level I evidence to guide treatment decisions in the second-line setting. The use of a VEGFr TKI in this 
setting is a reasonable option, however, this recommendation is made based on less than Level I evidence. ${ }^{38}$

Currently, Health Canada has not approved any agents in the third-line setting. However, there is data to support use of targeted therapies in this setting. In the RECORD-1 (Renal Cell cancer treatment with Oral RAD001 given Daily) trial of everolimus versus placebo, $25 \%$ of subjects randomized had received 2 VEGFR TKI therapies prior to enrolment and there was a significant improvement in PFS in the group receiving everolimus. ${ }^{20}$ Thus, everolimus would be a reasonable choice for patients in this setting.

\section{Role of cytoreductive nephrectomy}

\section{Cytoreductive nephrectomy should be considered in appropriately selected patients presenting with $\mathrm{mRCC}$.}

Recommendations for this section are based on Level I evidence in patients treated with interferon. Appropriately selected patients for cytoreductive nephrectomy $(\mathrm{CN})$ include: patients with a primary tumour amenable to surgical extirpation and a low risk of perioperative morbidity, patients with good performance status (ECOG 0 or 1 ), and patients without evidence of brain metastases. ${ }^{25,37-38} \mathrm{It}$ is important to ensure that patients undergoing $\mathrm{CN}$ meet these criteria to maximize benefit and that there is no concern about rapid disease progression that would require immediately starting systemic therapy.

At this point, there are no randomized data on the use of $\mathrm{CN}$ in the era of targeted therapy. Decisions are based on extrapolation from (1) the Interferon data; (2) retrospective North American data showing improved outcomes in patients with $\mathrm{CN}$ prior to targeted therapy; (3) the fact that most patients ( $>90 \%$ ) enrolled in the VEGFr TKI phase III clinical trials had a prior $\mathrm{CN}$; and (4) and clinical judgment. ${ }^{9,20,32,39-41}$ Prospective studies on the benefit of $\mathrm{CN}$ are required and several trials are currently underway. Canadian investigators are participating in the EORTC 30073 SURTIME trial.

In patients who do not undergo upfront $\mathrm{CN}$, but have a good response to VEGFrTKI or targeted therapy, limited metastatic disease and good performance status, $\mathrm{CN}$ may be considered in the course of their treatment.

\section{Role of metastatectomy}

In select patients with limited sites of metastatic disease and clinical stability resection of the metastatic disease may be reasonable.

There are no randomized trials demonstrating the benefit for metastatectomy in RCC. However, among patients with metachronous metastases after nephrectomy, about one- third are eligible for metastatectomy; several large cohorts report a 50\% 5-year survival following complete resection of metastases. ${ }^{37,42,43}$ Based on available observational data, patients most likely to benefit from metastatectomy are those diagnosed with metastases over 2 years following nephrectomy; those with isolated metastases; and those with favourable metastatic locations. A period of observation is reasonable to confirm that the metastatic disease is indolent.

\section{Role of radiation therapy}

Radiation therapy may be considered to control bleeding and pain from the primary tumour, to palliate symptoms from metastases and to stabilize brain metastases.

RCC is not a radio-resistant tumour and many patients can achieve palliation of symptoms related to their cancer through radiation therapy. New radiation techniques, such as stereotactic radiation therapy, may improve outcomes compared to traditional external beam radiation therapy; ongoing trials are in progress. ${ }^{44} \mathrm{Clinical}$ trials involving radiation should be supported.

\section{Role of bone targeted agents for patients with skeletal metastases}

About one-third of patients with metastatic RCC will develop bone metastases as part of their disease, ${ }^{45}$ which can lead to skeletal-related events (SRE). Currently available bonemodifying agents have been shown to reduce SREs in this population. In a phase III trial of zoledronic acid (ZA) versus placebo, a subset analysis of 74 RCC patients showed that administration of ZA compared to placebo resulted in a significant decrease in SREs in the ZA group (44\% compared to $74 \%$ in placebo). ${ }^{46}$ Specific results from this subgroup have been published separately. There was a significant reduction of SREs in the group receiving ZA $4 \mathrm{mg}$ intravenously monthly compared to placebo. ${ }^{47}$ Therefore, monthly administration of ZA is a reasonable option. Careful monitoring of renal function is required. Patients receiving bisphosphonates are at risk of hypocalcemia, so calcium and vitamin $\mathrm{D}$ supplements are recommended. However, since paraneoplastic hypercalcemia can also occur in RCC, monitoring of serum calcium levels is important. Patients starting any bone targeted therapy should ensure they have had a thorough dental exam prior to starting therapy and ongoing monitoring for osteonecrosis of the jaw (ONJ).

Denosumab is a receptor activator of nuclear factor kappa-B (RANK) ligand inhibitor. In a phase III trial of denosumab versus ZA to treat malignancy with bone metastases (excluding breast or prostate cancer patients), a subset of patients enrolled in this trial had metastatic RCC. This trial demonstrated non-inferiority for denosumab compared to 
ZA in terms of SRE reduction for the group overall, although no subgroup analysis for RCC patients has been conducted. ${ }^{48}$ In light of this, denosumab could also be considered a reasonable option for this population of patients. Calcium and vitamin D supplementation and careful serum calcium monitoring are also required for patients receiving denosumab, as well as a thorough dental examination and monitoring for ONJ.

\section{Summary}

Advanced RCC has seen many advances in treatment in the last several years, with the introduction of many targeted therapies into the treatment paradigm. Therapy should be individualized based on patient risk and each agent selected should be optimized in terms of dose and schedule to obtain maximal benefit. The optimal sequence of agents is still unclear and the subject of ongoing clinical trials. Multidisciplinary care is paramount in maximizing patient benefit. However, despite recent advances, many patients still die of metastatic RCC and ongoing support of clinical trials to further our knowledge in the field is essential.

Notes: Canadian Kidney Cancer Forum 2013, Toronto, Ontario. January 17-29, 2013.

Acknowledgements: Participants in the 4th Canadian Kidney Cancer Forum: Nils Kroeger, Michael Organ, Camilla Tajzler, Kelly Lane, Tran Truong, Mary-Lynn Reardon, Melanie Care, James Brugorolas, Craig Earle, Marg Fitch, Eamonn Maher, Catherine Madden, Paul Shay, Christopher Booth, Ronald Grant, Christian Kollmannsberger, Joy McCarthy, Joan Basiuk, Wendella Hamilton, Laura Legere, Paul O'Brien, Andrew Weller, Julie Ring, Nicole Giroux, Deb Maskens, Wally Vogel, Andrew Matthew, Patrick Cheung, Laurie Ailles, Vickie Baracos, Jennifer Jones, Suzanne Kamel-Reid, Arnim Pause, Sandra Turcotte, George Yousef, Zhihui (Amy) Liu, llias Cagiannos, Darrel Drachenberg, Antonio Finelli, Wassim Kassouf, Laurence Klotz, Stephen Pautler, Nicholas Power, Alan So, Simon Tanguay, Philippe Violette

Competing interests: Dr. Wood has received speaker fees, grants and/or travel assistance from Novartis. Dr. Soulières, Dr. Knox, Dr. Canil, Dr. Basappa and Dr. North have received funding. Dr. Reaume is on the advisory board for Pfizer, GSK and Novartis. Dr. Heng is a paid consultant for Bayer, Novartis and Pfizer. Dr. Bjarnason has received funding from Pfizer, Novartis and GSK.

This paper has been peer-reviewed.

\section{References}

1. Management of kidney cancer: Canadian Kidney Cancer Forum Consensus Statement. Can Urol Assoc J 2008;2:175-82.

2. Management of kidney cancer: Canadian Kidney Cancer Forum Consensus Update. Can Urol Assoc J 2009:3:200-4.

3. Management of Kidney Cancer: Canadian Kidney Cancer Forum Consensus Update 2011. Can Urol Assoc J 2012;6:16-22.
4 Canadian Cancer Statistics 2012; 2012: Toronto, Ontario.FutuAccessed July 25, 2013.

5. Alberta Health Services, A.P.G.T.T., Renal cell carcinoma. Clinical Practice Guideline GU-0032011.

6. Kassouf W, Siemens R, Morash C, et al. Follow-up guidelines after radical or partial nephrectomy for localized and locally advanced renal cell carcinoma. Can Urol Assoc J 2008;3:73-6.

7. Kidney Cancer Canada. http://www.kidneycancercanada.ca/. Accessed July 25, 2013.

8. Messing EM, Manola J, Wilding G, et al. Phase III study of interferon alfa-NL as adjuvant for resectable renal cell carcinoma: an Eastern Cooperative Oncology Group/Intergroup trial. J Clin Oncol 2003;21:1214-22. http://dx.doi.org/10.1200/JC0.2003.02.005

9. Motzer RJ, Bacik J, Schwartz LH, et al. Prognostic factors for survival in previously treated patients with metastatic renal cell carcinoma. J Clin Oncol 2004;22:454-63. http://dx.doi.org/10.1200/ JC0.2004.06.132

10. Heng DY, Xie W, Regan $M M$, et al. Prognostic factors for overall survival in patients with metastatic renal cell carcinoma treated with vascular endothelial growth factor-targeted agents: results from a large, multicenter study. J Clin Oncol 2009;27:5794-9. http://dx.doi.org/10.1200/JC0.2008.21.4809

11. Motzer RJ, Hutson TE, Tomczak $P$, et al. Sunitinib versus interferon alfa in metastatic renal-cell carcinoma. N Engl J Med 2007;356:115-24. ttp://dx.doi.org/10.1056/NEJMoa065044

12. Motzer RJ, Hutson TE, Tomczak P, et al. Overall survival and updated results for sunitinib compared with interferon alfa in patients with metastatic renal cell carcinoma. J Clin Oncol 2009;27:3584-90. http:// dx.doi.org/10.1200/JC0.2008.20.1293

13. Heng DY, Chi KN, Murray N, et al. A population-based study evaluating the impact of sunitinib on overall survival in the treatment of patients with metastatic renal cell cancer. Cancer 2009; 15:776-83. http:// dx.doi.org/10.1002/cncr.24051

14. Warren $M$, Venner $P$, North $S$, et al A population-based study examining the effect of tyrosine kinase inhibitors on survival in metastatic renal cell carcinoma in Alberta and the role of nephrectomy prior to treatment. Can Urol Assoc J 2009;3:281-9.

15. Bjarnason $G$, et al. Effect of an individualized dose/schedule strategy for sunitinib in metastatic renal cell cancer (mRCC) on progression-free survival (PFS): Correlation with dynamic microbubble ultrasound (DCE-US) data. 2011 Genitourinary Cancers Symposium. J Clin Oncol 2011;29 (suppl 7; abstr 356).

16. Sternberg CN, Davis ID, Mardiak J, et al. Pazopanib in locally advanced or metastatic renal cell carcinoma: results of a randomized phase III trial. J Clin Oncol 2010;28:1061-8. http://dx.doi.org/10.1200/ JC0.2009.23.9764

17. Motzer RJ, Hutson TE, Reeves J, et al. Randomized, open label phase III trial of pazopanib versus sunitinib in first line treatment of patients with metastatic renal cell carcinoma (mrcc): results of the COMPARZ trial. ESMO 2012, Vienna, Austria.

18. Motzer RJ, Nosov D, Eisen T, et al. Tivozanib versus sorafenib as initial targeted therapy for patients with advanced renal cell carcinoma: Results from a phase III randomized, openlabel, multicenter trial. J Clin Oncol 2012;30(suppl; abstr 4501).

19. Hudes $G$, Carducci $M$, Tomczak $P$, et al. Temsirolimus, interferon alfa, or both for advanced renal-cell carcinoma. N Engl J Med 2007;356:2271-81. http://dx.doi.org/10.1056/NEJMoa066838

20. Motzer RJ, Escudier B, Oudard S, et al. Phase 3 trial of everolimus for metastatic renal cell carcinoma: final results and analysis of prognostic factors. Cancer 2010;116:4255-65. http://dx.doi.org/10.1002/cncr.25219

21. Escudier B, Eisen T, Stadler WM, et al. Sorafenib in advanced clear-cell renal-cell carcinoma. N Engl J Med 2007;356:125-34. http://dx.doi.org/10.1056/NEJMoa060655

22. Escudier B, Pluzanska A, Koralewski $P$, et al. Bevacizumab plus interferon alfa-2a for treatment of metastatic renal cell carcinoma: a randomized, double-blind phase III trial. Lancet 2007;370:2103-11. http://dx.doi.org/10.1016/S0140-6736(07)61904-7

23. Rini, B.I., et al., Bevacizumab plus interferon alfa compared with interferon alfa monotherapy in patients with metastatic renal cell carcinoma:CALBG 90206. J Clin Oncol 2009. 26(33): p. 5422-5428. http:// dx.doi.org/10.1200/JC0.2008.16.9847

24. Cancer Care Ontario. Interleukin-2 in the treatment of patients with unresectable or metastatic renal cell cancer. Evidence based series 3-8-2, version 2. September 2011.

25. Cancer Care Ontario Genitourinary Cancer Practice Guidelines. https://www.cancercare.on.ca/toolbox/ qualityguidelines/diseasesite/genito-ebs/. Accessed July 25, 2013.

26. Negrier S, Perol D, Ravaud A, et al. Medroxyprogesterone, interferon alfa-2a, interleukin 2, or combination of both cytokines in patients with metastatic renal carcinoma of intermediate prognosis: results of a randomized controlled trial. Cancer 2007;1 10:2468-77. http://dx.doi.org/10.1002/cncr.23056

27. Gore ME, Szczylik C, Porta C, et al. Safety and efficacy of sunitinib for metastatic renal-cell carcinoma: an expanded-access trial. Lancet Oncol 2009;10:757-63. http://dx.doi.org/10.1016/S14702045(09)70162-7

28. Stadler WM, Figlin RA, McDermott DF, et al. Safety and efficacy results of the advanced renal cell carcinoma sorafenib expanded access program in North America. Cancer 2010;116:1272-80. http:// dx.doi.org/10.1002/cncr.24864 
29. Dutcher JP, de Souza P, McDermott D, et al. Effect of temsirolimus versus interferon-alpha on outcome of patients with advanced renal cell carcinoma of different tumor histologies. Med Oncol 2009;26:202-9. http://dx.doi.org/10.1007/s12032-009-9177-0

30. Choueiri TK, Plantade A, Elson P, et al. Efficacy of sunitinib and sorafenib in metastatic papillary and chromophobe renal cell carcinoma. J Clin Oncol 2008;26:127-31. http://dx.doi.org/10.1200/ JC0.2007.13.3223

31. Nanus DM, Garino A, Milowsky MI, et al. Active chemotherapy for sarcomatoid and rapidly progressing renal cell carcinoma. Cancer 2004;101:1545-51. http://dx.doi.org/10.1002/cncr.20541

32. Escudier B, Eisen T, Stadler WM, et al. Sorafenib for treatment of renal cell carcinoma: Final efficacy and safety results of the phase III treatment approaches in renal cancer global evaluation trial. J Clin Oncol 2009;2710:3312-8. http://dx.doi.org/10.1200/JC0.2008.19.5511

33. Rini BI, Escudier B, Tomczak P, et al. Comparative effectiveness of axitinib versus sorafenib in advanced renal cell carcinoma (AXIS): a randomised phase 3 trial. Lancet 2011;3;378:1931-9.

34. Motzer RJ, Basch E. Targeted drugs for metastatic renal cell carcinoma. Lancet 2007;370:2071-3. http:// dx.doi.org/10.1016/S0140-6736(07)61874-1

35. Motzer RJ, Escudier B, Oudard S. Efficacy of evirolimus in advanced renal cell carcinoma:a double blind,randomized, placebo-controlled phase III trial. Lancet 2008;372:449-56. http://dx.doi. org/10.1016/S0140-6736(08)61039-9

36. Hutson T, Escudier B, Esteban E, et al. Temsirolimus vs. Sorafenib as Second Line Therapy in Metastatic Renal Cell Carcinoma: Results from the INTORSECT Trial. 2012 ESMO Meeting, Vienna, Austria.

37. Patard JJ, Pignot G, Escudier B, et al. ICUD-EAU international consultation on kidney cancer 2010: treatment of metastatic disease. Eur Urol 2011;60:684-90. http://dx.doi.org/10.1016/i.eururo.2011.06.017

38. Grünwald $V$, Weikert $S$, Seidel $C$, et al. Efficacy of sunitinib re-exposure after failure of an mTOR inhibitor in patients with metastatic RCC. Onkologie 2011;34:310-4. http://dx.doi.org/10.1159/000328575

39. Flanigan RC, Mickisch G, Sylvester R, et al. Cytoreductive nephrectomy in patients with metastatic renal cancer: a combined analysis. J Urol 2004;171:1071-6. http://dx.doi.org/10.1097/01. ju.0000110610.61545.ae

40. Mickisch GH. Urologic approaches to metastatic renal cell carcinoma. Onkologie 2001;24:122-6. http:// dx.doi.org/10.1159/000050298
41. Choueiri TK, Xie W, Kollmannsberger C, et al. The impact of cytoreductive nephrectomy on survival of patients with metastatic renal cell carcinoma receiving vascular endothelial growth factor targeted therapy. J Urol 2011;185:60-6. http://dx.doi.org/10.1016/i.juro.2010.09.012

42. Eggener SE, Yossepowitch 0, Pettus JA, et al. Renal cell carcinoma recurrence after nephrectomy forlocalized disease: predicting survival from time of recurrence. J Clin Oncol 2006;24:3101-6. http://dx.doi. org/10.1200/JC0.2005.04.8280

43. Breau RH, Blute ML. Surgery for renal cell carcinoma metastases. Curr Opin Urol 2010;20:375-81. http://dx.doi.org/10.1097/MOU.0b013e32833c7ada

44. Stinaver MA, Kavanagh BD, Schefter TE, et al. Stereotactic body radiation therapy for melanoma and renal cell carcinoma: impact of single fraction equivalent dose on local control. Radiat Oncol 201 1;6:34. http://dx.doi.org/10.1186/1748-717X-6-34

45. Sahi C, Knox JJ, Clemons M, et al. Renal Cell Carcinoma Bone Metastases: Clinical Advances. Ther Adv Med Oncol 2010;2:75-83. http://dx.doi.org/10.1177/1758834009358417

46. Rosen LS, Gordon D, Tchekmedyian S, et al. Zoledronic acid versus placebo in the treatment of skeletal metastases in patients with lung cancer and other solid tumors: a phase III, double-blind, randomized trial-The Zoledronic Acid Lung Cancer and Other Solid Tumor Study Group. J Clin Oncol 2003;21:3150-7. http://dx.doi.org/10.1200/JC0.2003.04.105

47. Lipton A, Colombo-Berra A, Bukowski RM, et al. Skeletal complications in patients with bone metastases from renal cell carcinoma and therapeutic benefits of zoledronic acid. Clin Cancer Res 2004; 10:6397S-403S.

48. Henry DH, Costa L, Goldwasser F, et al. Randomized, double-blind study of denosumab versus zoledronic acid in the treatment of bone metastases in patients with advanced cancer (excluding breast and prostate cancer) or multiple myeloma. J Clin Oncol 2011;29:1125-32. http://dx.doi.org/10.1200/ JC0.2010.31.3304

Correspondence: Dr. Scott A. North, Associate Professor, Department of Oncology, University of Alberta, Medical Oncologist, Cross Cancer Institute, Edmonton, AB; Scott.North@albertahealthservices.ca 